\title{
BMJ Open Implementation of asthma guidelines to West Australian community pharmacies: an exploratory, quasi-experimental study
}

\author{
Kim Watkins, ${ }^{1}$ Michelle Trevenen, ${ }^{2}$ Kevin Murray, ${ }^{2}$ Peter A Kendall, ${ }^{1}$ \\ Carl R Schneider, ${ }^{3}$ Rhonda Clifford ${ }^{1}$
}

To cite: Watkins $\mathrm{K}$, Trevenen M, Murray K, et al. Implementation of asthma guidelines to West Australian community pharmacies: an exploratory, quasiexperimental study. BMJ Open 2016;6: 012369 . doi:10.1136/bmjopen-2016012369

- Prepublication history and additional material is available. To view please visit the journal (http://dx.doi.org/ 10.1136/bmjopen-2016012369).

Received 21 April 2016 Revised 15 July 2016 Accepted 19 July 2016

CrossMark

\begin{abstract}
${ }^{1}$ School of Medicine and Pharmacology, The University of Western Australia, Western Australia, Perth, Australia ${ }^{2}$ Centre for Applied Statistics, The University of Western Australia, Perth, Western Australia, Australia

${ }^{3}$ Faculty of Pharmacy, The University of Sydney, Sydney, Australia
\end{abstract}

Correspondence to Kim Watkins;

kim.watkins@uwa.edu.au

\section{ABSTRACT}

Objectives: Pharmacy assistants are often the first point of contact for patients presenting in community pharmacies. The current role of pharmacy assistants in the supply of asthma-reliever medications (short-acting $\beta$-agonists) was identified as a barrier to appropriate guideline-based care. The aim of this research was to devise and evaluate a team-based intervention to formalise the role of pharmacy assistants and to improve asthma guideline-based care in community pharmacy.

Design: A controlled pre-post intervention study was conducted in 336 metropolitan pharmacies located in Perth, Western Australia. Pharmacies were stratified into 2 groups (187 intervention and 149 control) based on known confounders for asthma control. The intervention was designed using a common-sense approach and resources developed included a checklist, videos and web page. Delivery was via workshops (25 pharmacies) or academic detailing (162 pharmacies). Pharmacy practice was assessed preintervention and postintervention via covert simulated patient methodology. Primary outcome measures included patient medical referral, device use demonstration and counselling, internal referral and/or direct involvement of a pharmacist in consultations.

Results: There was a significant increase in patient medical referral in intervention pharmacies from $32 \%$ to $47 \%$ ( $p=0.0007$ ) from preintervention to postintervention, while control pharmacies showed a non-significant decrease from $50 \%$ to $44 \%(p=0.22)$. Device counselling was not routinely carried out at any stage or in any cohort of this research and no significant changes in internal referral were observed.

Conclusions: Increases in medical referral indicate that asthma guideline compliance can be improved in community pharmacy if implementation employs a team-based approach and involves pharmacy assistants. However, results were variable and the intervention did not improve practice related to device counselling or internal referral/pharmacist involvement. Undertaking more workshops may have improved results. Guideline implementation in community pharmacy should consider the role of pharmacy

\section{Strengths and limitations of this study}

- This research used a thorough methodological approach to designing a 'common-sense' intervention to improve asthma guideline compliance.

- The intervention was atypical because it recognised the impact of pharmacy assistants on the professional practice of community pharmacists, which is often not considered, but is pivotal, in this setting.

- The intervention was unique in its team-based approach to community pharmacy practice to improve guideline compliance.

- Conclusions were limited by the lack of baseline equivalence of groups for the primary outcome of medical referral.

- Generalisability of the findings was reduced due to self-selection of workshop pharmacies. Self-selection can introduce bias, as participants are likely to be more motivated to improve professional practice.

assistants and how to overcome logistical barriers to pharmacy participation in implementation activities.

\section{BACKGROUND}

Asthma is a chronic respiratory disease characterised by recurrent episodes of wheezing, breathlessness, chest tightness and coughing. Although there is no cure for asthma, symptom control can be achieved in most patients with appropriate treatment. ${ }^{1}$ However, poor asthma control and inappropriate patient selfmanagement remain an issue in Australia and throughout the world, despite the availability of effective therapies. ${ }^{2-6}$

In Australia, a national classification system exists, called scheduling, which controls how medicines and chemicals are made available to the public. ${ }^{7}$ Schedules include S4 'Prescription Only', S3 'Pharmacist Only' 
and S2 'Pharmacy Only'. Asthma-reliever medications (short-acting $\beta$-agonists or SABAs) are classified as S3 and thus can be purchased without a prescription and without seeing a doctor, but under the direct supervision of a pharmacist. ${ }^{7}$ The community pharmacist is required to intervene and refer patients who may be inappropriately managing their condition. The term 'medical referral' is used to denote when community pharmacy staff instruct a patient to seek medical advice from a general practitioner (also called a physician or doctor). Research by Schneider $e t a l^{8}$ demonstrated that community pharmacists were not adequately fulfilling their role in appropriate referral. In response to the identified practice deficits, the Guidelines for provision of a Pharmacist Only medicine: short acting beta agonists (SABA guidelines) were endorsed by stakeholders and distributed to pharmacists by the Pharmaceutical Society of Australia (PSA) and The National Asthma Council of Australia (NAC) in 2011. ${ }^{9}$

In recent years, there has been a proliferation of clinical guidelines as a method to promote evidence-based healthcare. However, research suggests that clinicians frequently do not follow guidelines, resulting in an evidence-practice gap. ${ }^{10}{ }^{11}$ In the community pharmacy setting, research on clinical guidelines implementation is relatively new and there is little evidence on how to improve evidence-based practice. ${ }^{12}$ Most of the research to date has focused on the potential of pharmacists to achieve positive patient health outcomes through enhanced services delivery. ${ }^{13}{ }^{14}$ While this can indicate some of the issues relevant to suboptimal evidence-based practice, it does not fully explain the barriers to research translation and effecting change on the routine practice of community pharmacists.

The standards accreditation process (Quality Care Pharmacy Program) for community pharmacies in Australia requires pharmacy assistants, involved in handling non-prescription, scheduled medicine sales (including SABAs), to complete an online training unit by the Pharmacy Guild of Australia, while under supervision in the workplace. ${ }^{15}{ }^{16}$ Pharmacy assistants not working in accredited pharmacies and/or not servicing patients with non-prescription, scheduled medicines are not required to complete the Guild courses and may not receive any formalised training. However, with $90 \%$ of pharmacies across Australia currently accredited ${ }^{17}$ the majority of pharmacy assistants should receive some basic training.

Focus groups conducted with pharmacists and pharmacy assistants in 2012, regarding the utility of the SABA guidelines, indicated that there were many barriers to guideline-based practice. ${ }^{18}$ Particularly remarkable was the observation that pharmacy assistants who participated in the study were universally unaware of the guidelines, but were highly involved in the non-prescription supply of SABAs, rather than internally referring patients to the pharmacist. ${ }^{18}$ This lack of knowledge and high participation in supply was unexpected because of the mandatory training requirements for pharmacy assistants (in accredited pharmacies) and the legislation requiring pharmacists to be directly involved in patient assessment and supply of SABAs (S3 'Pharmacist Only' legislation). ${ }^{15} 1920$

The initial implementation strategy of the SABA guidelines had not addressed the issue of pharmacy assistant involvement and the barriers to internal referral of patients from pharmacy assistants to pharmacists. ${ }^{21}$ There was no acknowledgment of the workflows that exist in community pharmacy whereby the pharmacy assistant is often the first person to encounter patients requesting non-prescription asthma-reliever medications. There was only recognition of the legislation requiring pharmacist involvement; thus, the focus was to disseminate information about the guidelines to pharmacists. ${ }^{21}$ The focus group observations indicated that this was a significant oversight, particularly in light of previous research by Schneider $e t$ al. ${ }^{8}{ }^{22}$ Schneider $e t$ a ${ }^{8}{ }^{22}$ ascertained that outcomes for asthma patients, in terms of appropriate medical referral, were poorer when pharmacy assistants alone were involved in asthma-reliever medication sales.

Another barrier identified in non-prescription SABA supply was the difficulties pharmacy assistants encountered trying to engage with asthma patients, who they found resistant to questioning and impatient. ${ }^{18}$ Research shows that there is discordance between perceived asthma control and actual symptomatic control, ${ }^{23-26}$ so it is not unexpected that patients with asthma are resistant to engagement: they do not perceive they need support. Unfortunately, poor patient disclosure of health information in community pharmacy is an issue, which can influence appropriateness of outcomes. ${ }^{27}{ }^{28}$ Where such barriers exist, the recommendation is for interventions that promote better communication between patients and pharmacy staff. ${ }^{27}$

It was evident that workflows supporting the involvement of pharmacy assistants, unaware of the SABA guidelines and experiencing difficulties with engagement of patients with asthma, were creating a barrier to pharmacist participation, appropriate guideline-based assessment and patient medical referral. Therefore, the aim of this research was to devise and evaluate a teambased intervention to formalise the role of pharmacy assistants in order to improve asthma guideline-based care in community pharmacy.

\section{METHODS \\ Design of a 'common-sense' intervention to overcome an identified barrier}

'Common-sense' interventions are designed using a pragmatic and logical approach based on empiric evidence and past experience. ${ }^{29}$ The design of this intervention was undertaken by researchers with experience and knowledge of community pharmacy practice, based on evidence obtained from the scientific literature and information from focus groups. Researchers, from their 
experience in community pharmacy, recognised that activities undertaken in the pharmacy required team effort and team support. Evidence from the literature was gleaned by undertaking a systematic review to examine the effectiveness of implementation strategies for clinical guidelines to community pharmacy. ${ }^{12}$ There was little evidence that was conclusive about the best approach to implementation of guidelines in community pharmacy, but there was an observation that it was important to consider the role of non-professional staff (pharmacy assistants), due to the influence they can have on the practice of pharmacists. This observation is consistent with the findings of Schneider et $a t^{22}$ who demonstrated improved patient outcomes associated with patient referral from assistants to pharmacists. However, few implementation interventions had previously included pharmacy assistants. Also there were few studies based on and demonstrating the benefit of behavioural theory in intervention design. Reviews on guideline implementation from other settings were also considered and there was a general consensus that it was important to identify barriers and tailor interventions to overcome them. ${ }^{30}{ }^{31}$ Focus groups were used to map barriers and facilitators of guideline implementation and asthma management. ${ }^{18}$ Many barriers were identified, but two key issues were used in developing the intervention. Communication issues were problematic due to the discordant views of patients and health professionals on asthma management. It was also evident from the focus group discussions that pharmacy assistants played a significant role in assessing and counselling patients but had problems engaging with patients. A variety of intervention options were considered, including smartphone apps, legislative changes and patient health promotional activities. Ultimately formalising an appropriate role for pharmacy assistants to support pharmacists was chosen. This option was practical, relatively simple, unique and supported by the evidence and preliminary research.

\section{Design logistics}

Small group workshops were chosen as the delivery mode for the 'common-sense' intervention. Poor uptake of workshop invitations required adaptation of the intervention and subsequently academic detailing was undertaken in pharmacies in the intervention group that did not participate in workshops. Academic detailing was a reasonable adaptation based on evidence of effectiveness of this strategy from the literature,,$^{32} 33$ and the fact that it uses face-to-face interaction in the practice setting, as did the workshops. Workshops and academic detailing were completed between October 2013 and March 2014.

The primary author (KW) conducted the workshops. As a community pharmacist and pharmacy proprietor, the primary author had a good understanding of the workshop material and of pharmacy staff and their working environment. A background of teaching pharmacy practice and communication skills provided the necessary skillset to conduct workshops. Workshops were conducted in each pharmacy and all staff members of that pharmacy were encouraged to participate. Workshops ran for between 1 and 2 hours depending on the level of group discussion. Conducting training in-store allowed for tailoring of information based on the observed environment, current workflows and staff relating previous experiences with patient engagement. The components of the intervention included group education and communication skills training. Information was provided about asthma, the patient perspective, improving communication, legislative requirements, the SABA guidelines and remuneration opportunities in practice. A Microsoft Power-Point presentation, two videos and checklist tool were developed specifically for the workshop. Educational materials from the NAC and Asthma Foundation of Western Australia, as well as copies of the SABA guidelines from the PSA, were provided to pharmacies.

Workshops were interactive and group discussion was used to motivate staff and give them 'ownership' of the optimum way to use the resources. It was important to include pharmacists in the intervention and not just pharmacy assistants. During the intervention design process, recognition was given to the fact that the community pharmacy functions as a whole system and pharmacy assistants and pharmacists needed to support each other to achieve the desired outcomes. To maintain practice-change post workshop, pharmacies were provided a DVD of all workshop content (including the video material), notepads of checklists ready to implement and a link to a web page containing PDF documents of the guidelines and checklist that could be printed (http://www.asthma-pharmacy.org). They were also encouraged to contact the research team if they had any issues or successes.

Academic detailing is also known as educational outreach. It involves trained researchers visiting health professionals in the workplace to provide them information on how to change practice. Three pharmacists were trained by the primary author (KW) to conduct detailing visits. Each academic detailing visit took $\sim 15 \mathrm{~min}$. The trained academic detailers were given a standardised protocol to ensure uniformity in the information provided to the community pharmacies. The information and resources provided in the academic detailing visits were consistent with the information provided in the workshop. The difference was that the information was provided to the pharmacist-in-charge at the time of the visit, rather than the pharmacy staff as a team. This required the pharmacist-in-charge to act as a disseminator of information and driver of practice change. It also did not allow for tailoring of the information via group discussion as was achieved in workshops. Pharmacies received, as part of the academic detailing visit, a copy of the SABA guidelines, a DVD of all workshop content (including the video material), notepads of checklists ready to implement and a link to the asthma-pharmacy web page (http://www.asthma-pharmacy.org). 


\section{Resources}

\section{Checklist development}

A tool was devised centred on the assessment information outlined in the SABA guidelines (see online supplementary material). The concept was based on an existing Emergency Contraception checklist $^{34}$ that is accepted and widely used by pharmacies in Western Australia. ${ }^{35}$ It was anticipated that an equivalent tool for provision of SABAs would be relatively easy to incorporate into practice. The Asthma Medication Request Checklist is a 7-item simple tick-box tool, which can be completed by patients alone or with the support of a pharmacy assistant, within a couple of minutes.

It aimed to influence all of the target outcomes by acting as a prescreening tool, an internal referral tool and time-management tool. An incentive to using the checklist was that it complied with documentation requirements to access remuneration pathways for clinical service provision and meet accreditation standards. An expert panel of pharmacists was used to refine the tool and it was formatted in a way consistent with other tools promoted by PSA. As a communication tool/ patient engagement tool, the checklist allowed pharmacy assistants to collect information from patients not receptive to answering questions. It achieved this in a few ways. The form added formality to the interaction making patients feel that it was important to answer the questions. It overcame patient frustration with the inadequate communication skills of pharmacy assistants. Pharmacy assistants were empowered to collect information where previously they had been reluctant to ask questions for fear of 'upsetting patients'. It also avoided a situation whereby patients were asked the same questions by assistants and then again by pharmacists. Collecting the information was time effective, which was important in situations where impatience was undermining interactions. It also allowed pharmacists to have more in-depth and personalised discussions based on the information already gathered. Such tailored conversations were more relevant, meaningful and interesting to patients. The checklist was an alternative way of engaging with patients who had become accustomed to pharmacy staff asking 'annoying' questions in an unimaginative way, or not making any assessments at all. Staff were reminded that filling in the checklist was not the goal. The checklist was simply a tool to help them engage and achieve appropriate guideline-based care of the patient.

\section{Training videos}

Two videos were produced for the training workshops. The first video was a patient story describing a near death experience with asthma. It not only served to provide information to workshop participants about health consequences of asthma but also provided insight into patient behaviours and attitudes that may undermine their health. The patient story assisted in persuading pharmacy staff (assistants and pharmacists) to persevere with tackling the issue of asthma. Understanding the patient perspective was also used as a method of enhancing communication and a more empathic approach by pharmacy staff. The second video was a role-play video used to demonstrate the difficulties with patient engagement and also to model the desired behaviour and use of resources. Humour in the videos was used to facilitate discussion. By sharing stories of problematic patient encounters, staff were able to reflect on how to improve patient engagement in the future.

\section{Trial design}

The study was a controlled trial with a control group (no intervention) and an intervention group conducted in community pharmacies in Perth, Western Australia. The groupings were based on geographical location. Perth is an urban centre with development extending along the coastline of the Indian Ocean and divided by the Swan River. To the east of the city is a steep escarpment known as the Darling Scarp. The areas chosen were the south and north metropolitan areas of Perth, Western Australia. Eastern suburbs were excluded due to possibility of environmental and socioeconomic factors influencing results, as indicated by a report on geographic distribution of asthma hospitalisations from Australia. ${ }^{36}$ The purpose of the stratification was to reduce potential cross-contamination of data using the Swan River as a geographical barrier. A randomised, prebaseline, pilot assessment was used to demonstrate that the selected north/south groups were equivalent. Assessments were performed at baseline and postintervention. The study was performed between September 2012 and June 2014. The sample size was determined by including all pharmacies in the south and north Metropolitan area of Perth, Western Australia, listed on the Pharmacy Registration Board of Western Australia Premises Register. ${ }^{37}$ Hospital pharmacies were excluded from the study. The primary author performed all group allocations.

\section{Prebaseline pilot testing}

Simulated shoppers visited a random sample of 60 pharmacies in the non-intervention and intervention groups (30 south and 30 north) in September 2012. This pilot testing was undertaken before baseline data collection started, to validate the stratification method chosen. There were no significant differences in the cohorts for the primary outcome of appropriate medical referral (63.3\% referral south vs $56.7 \%$ referral north, $\mathrm{p}=0.60)$.

\section{Implementation of the intervention}

Each community pharmacy in the intervention area (north metropolitan) was invited to participate in an individual, in-store, small group, asthma-training workshop. An initial invitation letter was sent with follow-up via phone call and email. The invitation encouraged all pharmacy staff to attend, including professional and non-professional staff; full-time, part-time and casual staff. The primary author enrolled all workshop 
participants. Academic detailing of workshop content was provided to pharmacies in the intervention area that did not participate in workshops. Academic detailing was performed using a 'cold calling' method with no prior appointment. This method was selected after consultation with researchers with previous experience in academic detailing in community pharmacy. With visits being conducted during normal working hours, interruptions to conversations were inevitable. To minimise the disruptions, detailing visits were scheduled between 10:00 and 16:00. Detailers were limited to a maximum of eight detailing visits in 1 day to avoid fatigue.

\section{Data collection}

Data collection was via covert simulated patient methodology. As per ethics approval, pharmacies were not informed that they would receive simulated patient visits. This methodology has been widely and successfully used in the community pharmacy setting by pharmacy practice researchers at the Centre for Optimisation of Medicines at the University of Western Australia. ${ }^{8} 22$ 38-40 A 1-day training session was held for four research assistants who were provided information about the scenario, data collection and data entry. The training session provided opportunities for role-play and refinement of tools where necessary. Following the training day, the research assistants piloted the methodology in eight pharmacies to ensure fluency in the scenario and to test for unforeseen issues. The research assistants included a female pharmacist aged 25-30 years, two university students aged 20-25 years (man and woman) and a woman aged $45-50$ years. Simulated patients were blinded to the group allocation.

\section{Scenario}

The scenario involved a simulated patient presenting to a community pharmacy asking 'Could I buy a Ventolin please?' Ventolin is a common brand of asthma-reliever medication used in Australia. Although the simulated patients could provide more information upon request, they were instructed not to volunteer information. Table 1 outlines the scenario description. If pharmacy staff sought further information, patient assessment would reveal a patient with poorly controlled asthma and poor inhaler technique. This required inhaler technique training and immediate medical referral in accordance with guidelines. ${ }^{1}{ }^{9}$ Simulated patients were provided an empty Ventolin inhaler if asked to demonstrate inhaler technique.

\section{Outcomes}

The primary outcomes of interest related to guideline and legislative compliance. These included patient medical referral to a doctor for uncontrolled asthma, inhaler device demonstration and increases in pharmacy assistant to pharmacist internal referrals or direct

\section{Table 1 Simulated patient scenario description}

\begin{tabular}{|c|c|c|}
\hline \multirow{3}{*}{$\begin{array}{l}\text { Patient request } \\
\text { Possible questions and answers based } \\
\text { on WWHAM guidelines }\end{array}$} & \multicolumn{2}{|l|}{ ‘Could I buy a Ventolin® please?’ } \\
\hline & Who is the patient? & 'Me' \\
\hline & What are the symptoms? & 'Breathlessness' \\
\hline & How is your asthma? & 'I have been feeling a bit breathless lately’ \\
\hline & $\begin{array}{l}\text { How long have you had asthma/ } \\
\text { symptoms? }\end{array}$ & $\begin{array}{l}\text { 'Had asthma for years but getting worse over } \\
\text { the last month' }\end{array}$ \\
\hline & $\begin{array}{l}\text { What treatments have you tried for } \\
\text { these symptoms? }\end{array}$ & $\begin{array}{l}\text { 'I use Ventolin metered dose inhaler and } \\
\text { Seretide metered dose inhaler' }\end{array}$ \\
\hline & $\begin{array}{l}\text { Do you have any other medical } \\
\text { conditions/medications? }\end{array}$ & 'No' \\
\hline & Do you have any allergies? & 'No allergies' \\
\hline \multirow[t]{10}{*}{ Additional information } & \multicolumn{2}{|c|}{ Asthma has been getting worse over last month } \\
\hline & \multicolumn{2}{|c|}{$\begin{array}{l}\text { For the last month has been using Ventolin } 2 \text { puffs once every day to relieve } \\
\text { symptoms }\end{array}$} \\
\hline & \multicolumn{2}{|c|}{ Has been using Seretide regularly at a dose of 2 puffs twice a day for 2 years } \\
\hline & \multicolumn{2}{|c|}{ The last time they saw a physician/doctor was 'ages ago' } \\
\hline & \multicolumn{2}{|c|}{ Has not ever been admitted to hospital with asthma before } \\
\hline & \multicolumn{2}{|c|}{ Does not have a written asthma action plan } \\
\hline & \multicolumn{2}{|c|}{ Does not know the 'rule of 4 's'-what to do in an emergency } \\
\hline & \multicolumn{2}{|c|}{ Trigger factors for asthma include pet hair and pollen } \\
\hline & \multicolumn{2}{|c|}{ Ventolin=salbutamol $100 \mu \mathrm{g}$ per actuation (blue inhaler) } \\
\hline & \multicolumn{2}{|c|}{ Seretide=fluticasone/salmeterol $250 \mu \mathrm{g} / 25 \mu \mathrm{g}$ per actuation (purple inhaler) } \\
\hline Inhaler technique & \multicolumn{2}{|c|}{$\begin{array}{l}\text { If inhaler technique is assessed, the inhaler is not shaken before use and the } \\
\text { breath is not held after inhalation }\end{array}$} \\
\hline Appropriate outcome & \multicolumn{2}{|c|}{ A. Medical referral for poor asthma control } \\
\hline & \multicolumn{2}{|c|}{ B. Correction of poor inhaler technique } \\
\hline
\end{tabular}


involvement of a pharmacist in consultations. Secondary outcomes included use of the Asthma Medication Request Checklist introduced in the intervention and increases in the number of appropriate assessment questions asked by pharmacy staff (pharmacists and pharmacy assistants).

\section{Statistical analysis}

Percentages and counts (N) were calculated for each of the categorical variables for the intervention and nonintervention pharmacies at pre-post intervention time points. To investigate whether north and south pharmacies were equivalent, prebaseline $\chi^{2}$ tests (or Fisher's exact tests where appropriate) were conducted to compare whether specific questions were asked. To investigate bias between simulated patients, a $\chi^{2}$ test was conducted comparing the primary outcome of patient medical referral. Binary logistic regression was used to investigate differences in whether specific questions were asked (event='Yes') between cohorts (intervention and non-intervention) and times (each model also contained their respective interaction). ORs, 95\% CIs and $\mathrm{p}$ values are provided. Linear regression was conducted to analyse differences in continuous outcomes between cohorts and times. Mean differences, SE of the differences and $p$ values are provided. Data were analysed using the $\mathrm{R}$ (Version 3.1.3) environment for statistical computing ( $\mathrm{R}$ Core Team. R: a language and environment for statistical computing, 2015. http://www. r-project.org).

\section{RESULTS}

\section{Participant flow}

Simulated patient visits were conducted in 336 pharmacies at two time points (preintervention (January 2013-March 2013) and postintervention (April 2014June 2014)). Of these, 187 pharmacies received an intervention (north metropolitan) and the remaining 149 pharmacies (south metropolitan) did not. Workshop interventions were conducted in 25 pharmacies with 137 staff members. Academic detailing was undertaken in 162 pharmacies. A total of three pharmacies were excluded from the analyses due to incomplete data. Figure 1 shows the flow of participants through the intervention.

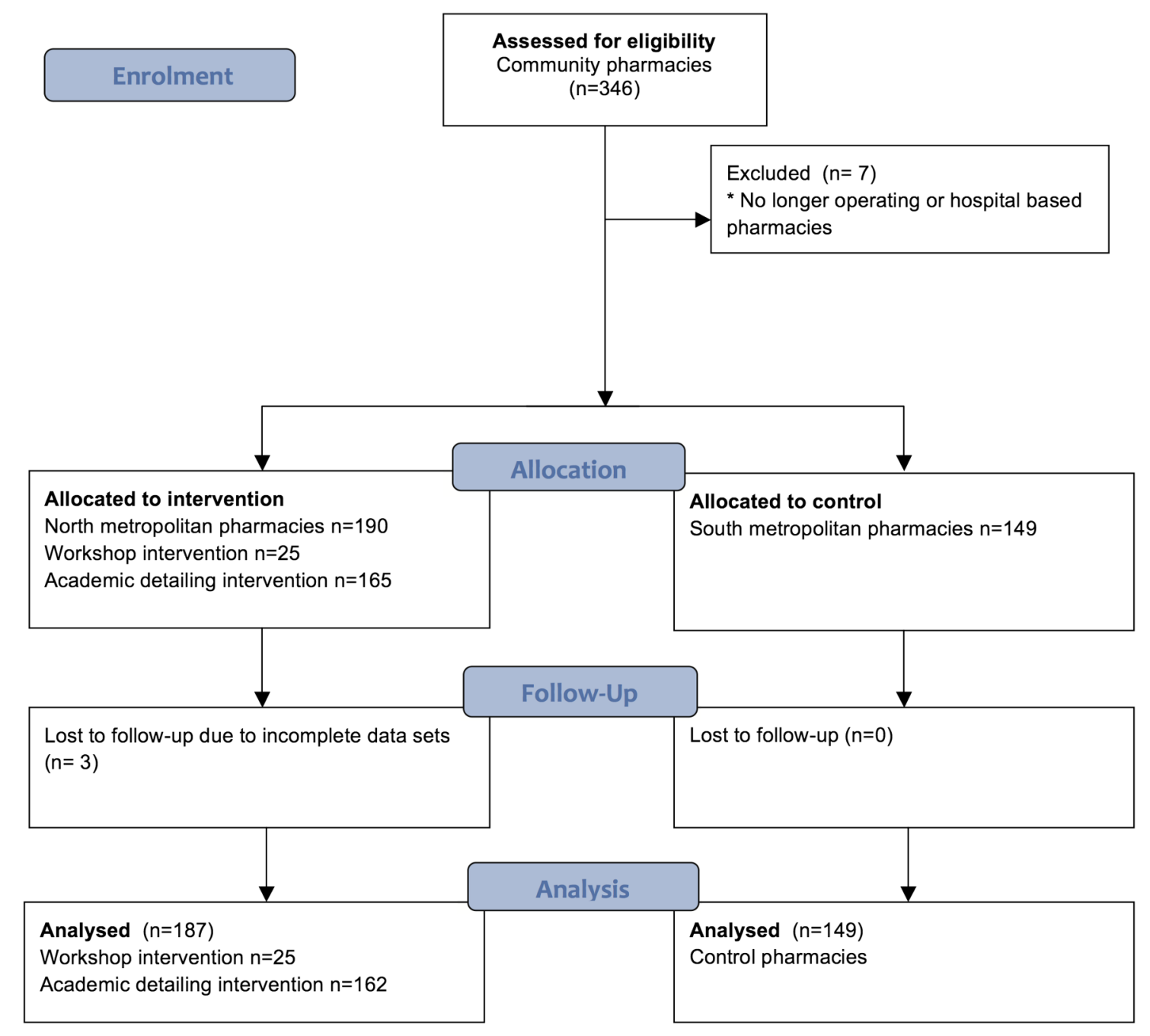

Figure 1 CONSORT flow chart of participants. 
Table 2 Descriptive data-intervention study

\begin{tabular}{|c|c|c|c|c|c|c|c|}
\hline \multirow{2}{*}{$\begin{array}{l}\text { Intervention cohorts } \\
\text { Time of simulated patient } \\
\text { assessment (preintervention } \\
\text { or postintervention) }\end{array}$} & \multicolumn{3}{|c|}{$\begin{array}{l}\text { North metropolitan (intervention cohort) } \\
n=187\end{array}$} & \multicolumn{3}{|c|}{$\begin{array}{l}\text { South metropolitan (control) } \\
n=149\end{array}$} & \multirow{2}{*}{$\begin{array}{l}\text { Cohort } \\
\text { comparisons } \\
\text { p Value comparing } \\
\text { differences in time } \\
\text { between cohorts }\end{array}$} \\
\hline & $\begin{array}{l}\text { Pre, } \\
\text { count (\%) }\end{array}$ & $\begin{array}{l}\text { Post, } \\
\text { count (\%) }\end{array}$ & $\begin{array}{l}\text { p Value comparing } \\
\text { pre to post of } \\
\text { intervention cohort }\end{array}$ & $\begin{array}{l}\text { Pre, } \\
\text { count (\%) }\end{array}$ & $\begin{array}{l}\text { Post, } \\
\text { count (\%) }\end{array}$ & $\begin{array}{l}\text { p Value comparing } \\
\text { pre to post of } \\
\text { control cohort }\end{array}$ & \\
\hline \multicolumn{8}{|l|}{ Counsellor demographics } \\
\hline \multicolumn{8}{|l|}{ Position of first counsellor* } \\
\hline Pharmacist & $55(29.4)$ & $55(29.4)$ & NS & $33(22.2)$ & $44(29.5)$ & NS & NS \\
\hline Pharmacy assistant & $31(16.6)$ & $38(20.3)$ & NS & $37(24.8)$ & $29(19.5)$ & NS & NS \\
\hline Other & $10(5.3)$ & $7(3.7)$ & NS & 17 (11.4) & $9(6.0)$ & NS & NS \\
\hline Unsure & $91(48.7)$ & $87(46.5)$ & NS & $62(41.6)$ & $67(45.0)$ & NS & NS \\
\hline \multicolumn{8}{|c|}{ Change in counsellor (when first consultant was a pharmacy assistant at both time points) } \\
\hline No change & $5(83.3)$ & $4(66.7)$ & NS & $8(66.7)$ & $7(58.3)$ & NS & NS \\
\hline Assistant to pharmacist & $0(0.0)$ & $1(16.7)$ & NS & $3(25.0)$ & $1(8.3)$ & NS & NS \\
\hline Pharmacist consulted & $1(16.7)$ & $1(16.7)$ & NS & $1(8.3)$ & $4(33.3)$ & NS & NS \\
\hline \multicolumn{8}{|l|}{ Consultation details } \\
\hline \multicolumn{8}{|l|}{ Waiting time (busyness measure) $†$} \\
\hline None & $155(82.9)$ & $170(90.9)$ & 0.0236 & $124(83.2)$ & $135(90.6)$ & 0.0428 & NS \\
\hline $1-5 \min$ & $31(16.6)$ & $16(8.6)$ & NS & $25(16.8)$ & $13(8.7)$ & NS & \\
\hline Over 5 min & $1(0.5)$ & $1(0.5)$ & NS & $0(0.0)$ & $1(0.7)$ & NS & \\
\hline \multicolumn{8}{|l|}{ Patient assessment } \\
\hline \multicolumn{8}{|l|}{ Questions (frequently asked) } \\
\hline Is this product for you? & $125(66.8)$ & $124(66.3)$ & NS & $124(83.2)$ & $111(74.5)$ & NS & NS \\
\hline Have you used this product before? & $77(40.1)$ & $58(31.0)$ & NS & $67(45.0)$ & $50(33.6)$ & 0.0467 & NS \\
\hline How often are you using your reliever? & $60(32.1)$ & $71(38.0)$ & NS & $63(42.3)$ & $54(36.2)$ & NS & NS \\
\hline Have you had a review by a doctor? & $48(25.7)$ & $45(24.1)$ & NS & $43(28.9)$ & 27 (18.2) & NS & NS \\
\hline Are you using a preventer? & $24(12.8)$ & $92(49.2)$ & $<0.0001$ & $32(21.5)$ & $88(59.1)$ & $<0.0001$ & NS \\
\hline \multicolumn{8}{|l|}{ Inhaler technique questions asked } \\
\hline $\begin{array}{l}\text { When did you last have your device technique } \\
\text { checked? }\end{array}$ & $1(0.5)$ & $0(0.0)$ & Not performed & $0(0.0)$ & $0(0.0)$ & Not performed & Not performed \\
\hline Can you show me your technique? & $1(0.5)$ & $2(1.1)$ & Not performed & $0(0.0)$ & $0(0.0)$ & Not performed & \\
\hline \multicolumn{8}{|l|}{ Demonstration of technique } \\
\hline $\begin{array}{l}\text { Device technique demonstrated (NB: } \\
\text { Demonstrated technique in all instances was } \\
\text { incorrect) }\end{array}$ & $2(1.1)$ & $1(0.5)$ & Not performed & $0(0.0)$ & $0(0.0)$ & Not performed & \\
\hline \multicolumn{8}{|l|}{ Medication counselling information provided } \\
\hline \multicolumn{8}{|l|}{ Information given (most frequently) } \\
\hline Information given on dosage & $20(10.7)$ & 25 (13.3) & NS & $19(12.8)$ & $15(10.1)$ & NS & NS \\
\hline Information given on duration/frequency of use & $13(7.0)$ & $34(18.1)$ & 0.0013 & $25(16.8)$ & 26 (17.4) & NS & 0.0201 \\
\hline \multicolumn{8}{|l|}{ Discussions about medical referral } \\
\hline Referral to a healthcare professional & $59(31.6)$ & & 0.0007 & $75(50.3)$ & 65 (43.6) & NS & 0.0019 \\
\hline Immediate referral recommended (when referred) & $5(8.5)$ & & NS & $6(8.0)$ & $8(12.3)$ & NS & NS \\
\hline
\end{tabular}

Time of simulated patient

assessment (preintervention

Counsellor demographics

Position of first counsellor

NS

$10(5.3)$

hange in counsellor (when first consultant was a pharmacy assistant at both time points)

$1(16.7)$

NS

sultation details

Waiting time (busyness measure) $\dagger$

None

$1-5 \mathrm{~min}$

ent assessment

Have you had a review by a doctor?

$77(40.1)$

$58(31.0)$

$92(49.2)$

$43(28.9) \quad 27(18.2)$

$32(21.5) \quad 88(59.1)$

Continued 


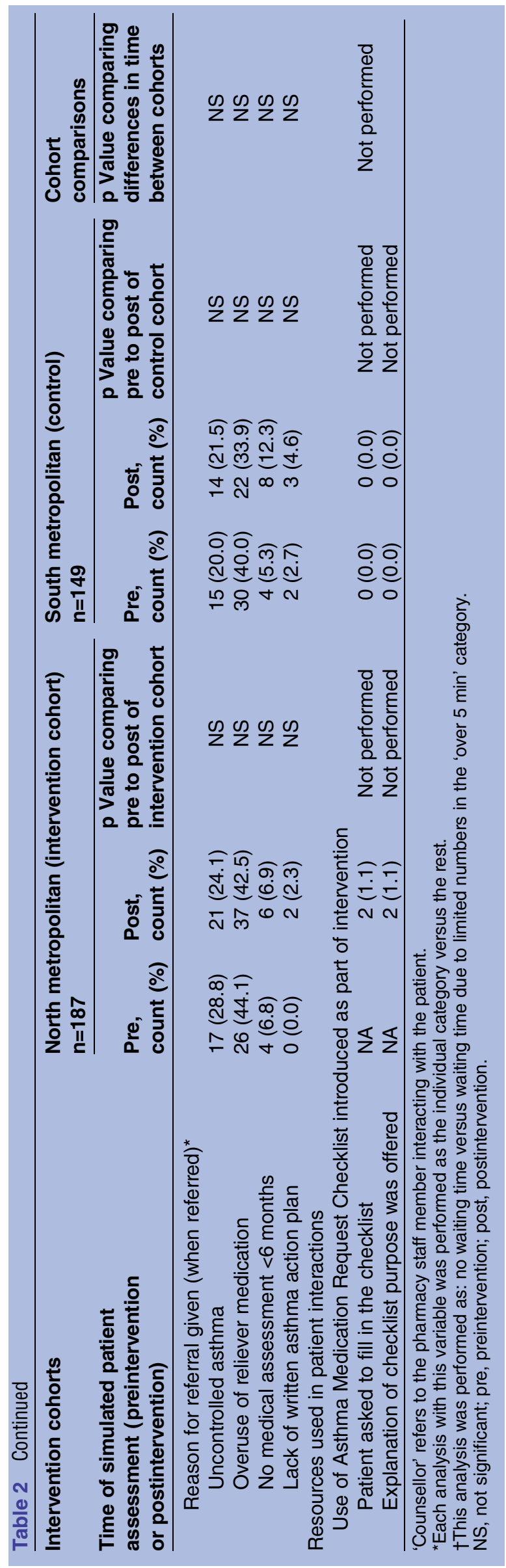

Simulated patient assessments

Information recorded by simulated shoppers included pharmacy details, counsellor details, consultation details, patient assessment, device use assessment, patient counselling and resource use (eg, Asthma Medication Request Checklist). No bias was detected as a result of differences between simulated patients. There were no observed significant differences for the primary outcome of patient medical referral between simulated patients.

\section{Pharmacy, counsellor and consultation details}

Pharmacy demographics were recorded. This included the location (street, medical centre, shopping centre and other) and type (independent or chain) of each pharmacy. The term 'counsellor' refers to the pharmacy staff member interacting with the patient: assessing their needs and/or providing advice. Table 2 outlines the pharmacy, counsellor and consultation characteristics that were assessed. Few of the characteristics were observed to be significantly different over time in either the intervention or non-intervention areas. In both cohorts, at both time points, the position of the counsellor (either pharmacist or assistant) was unclear in almost $50 \%$ of simulated patient visits. There were no significant changes to initial pharmacist involvement in consultations. There were also no increases in internal referral, as indicated by a change in counsellor from pharmacy assistant to pharmacist, as a result of the intervention. The intervention and non-intervention cohorts significantly decreased their patient waiting times between the pre and post time points, but there were no significant differences in the decreases in pharmacy busyness between cohorts (intervention and non-intervention).

\section{Patient assessment}

Table 2 indicates the results of patient assessment by pharmacies. There was little difference in the assessment questions asked between both time points and between pharmacies. One exception was the question about preventer use. Analysis indicated that control and intervention pharmacies were more likely over time to ask about preventer use (post vs pre: OR 5.89, 95\% CI 4.11 to $8.45, \mathrm{p}<0.0001)$. The total number of assessment questions asked was significantly related to the intervention and time $(p=0.0069)$. Figure 2 indicates that the mean total number of assessment questions asked at baseline was higher in the control cohort compared to the intervention cohort (mean difference $0.69, \mathrm{SE}=0.21, \mathrm{p}=0.0012$ ) and this declined over time for the control cohort (mean difference $=0.56, \mathrm{SE}=0.20, \mathrm{p}=0.0062$ ), whereas in the intervention cohort, the mean total number of assessment questions did not significantly change over time (mean difference $=0.05, \mathrm{SE}=0.21, \mathrm{p}=0.82$ ).

\section{Device use and counselling}

Device counselling was not routinely carried out at any stage or in any cohort of this research. As indicated in table 2, almost all counselling points recorded were 
No Intervention

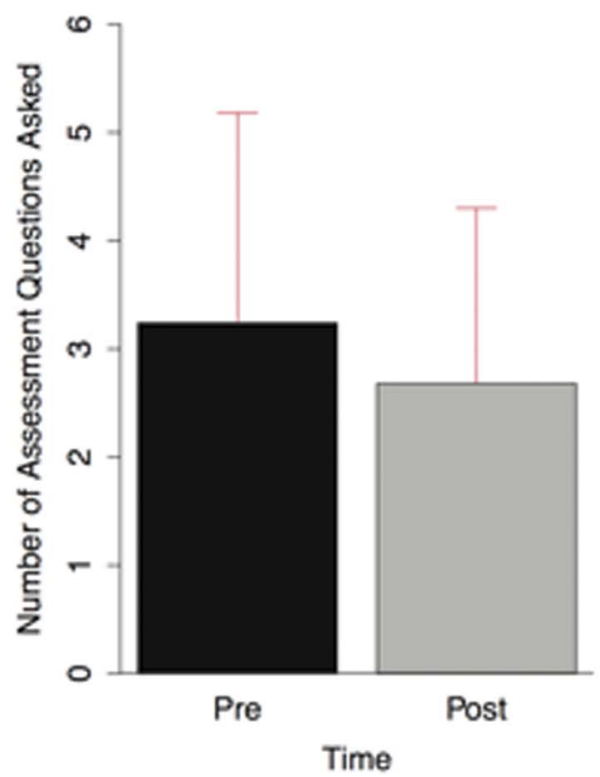

Intervention

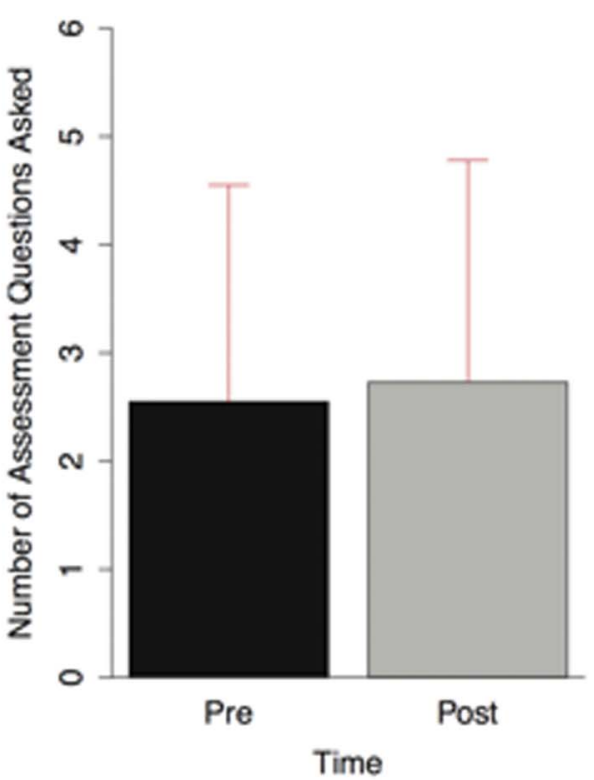

\begin{tabular}{|l|l|l|l|l|l|}
\hline Cohorts & \multicolumn{2}{|l|}{$\begin{array}{l}\text { North metropolitan } \\
\text { (Intervention cohort) } \\
\mathbf{n = 1 8 7}\end{array}$} & $\begin{array}{l}\text { South metropolitan } \\
\text { (Control) } \\
\mathbf{n = 1 4 9}\end{array}$ & $\begin{array}{l}\text { p-value } \\
\text { comparing the } \\
\text { difference in } \\
\text { time between } \\
\text { cohorts }\end{array}$ \\
\hline $\begin{array}{l}\text { Time of simulated patient assessment } \\
\text { (Pre-intervention or Post-intervention) }\end{array}$ & Pre & Post & Pre & Post & \\
\hline $\begin{array}{l}\text { Mean total number of assessment } \\
\text { questions }\end{array}$ & 2.55 & 2.73 & 3.24 & $2.68^{*}$ & 0.0069 \\
$\begin{array}{l}\text { Standard deviation } \\
\text { Minimum }\end{array}$ & 2.00 & 2.05 & 1.94 & 1.62 & \\
Median & 0 & 0 & 0 & 0 & \\
Maximum & 2 & 2 & 3 & 3 & \\
\hline
\end{tabular}

* Indicates that post measurement is significantly different to pre measurement for that particular cohort

Figure 2 Mean total number of assessment questions asked.

similar at both time points and in all pharmacies. The exceptions were patient medical referral and information provided about medication duration/frequency of use. Non-intervention pharmacies showed a nonsignificant decrease in patient medical referral from $50 \%$ to $44 \% \quad(p=0.22)$. In comparison, intervention pharmacies showed a significant increase in patient medical referral from $32 \%$ to $47 \% \quad(p=0.0007)$. Baseline medical referral was significantly different between cohorts. The non-intervention cohort was significantly more likely to refer at baseline (intervention vs control at time preintervention: OR $0.45,95 \%$ CI 0.29 to $0.71, \mathrm{p}=0.0005)$. Postintervention, there was no significant difference in medical referral between the intervention and control cohort (intervention vs control at postintervention: OR $1.13,95 \%$ CI 0.74 to $1.75, \mathrm{p}=0.56)$. Pharmacies in the intervention cohort were significantly more likely to discuss duration/frequency of reliever medication usage postintervention than preintervention (OR 2.97, 95\% CI 1.53 to 5.77, $\mathrm{p}=0.0013$ ). This was significantly different to the observations in the non-intervention group where discussions about duration/frequency of reliever use in this cohort remained the same over the two time periods $(\mathrm{p}=0.0201)$.

Figure 3 illustrates some of the significant outcomes across the cohorts and over time.

\section{Resource use}

Of the 187 pharmacies that received the intervention, 2 pharmacies (1\%) used the Asthma Medication Request Checklist introduced. One pharmacy was from the workshop cohort and one pharmacy was from the academic detailing cohort. Correspondence with the primary author indicated that more pharmacies were using the resource, but this was not evident in the simulated shopping results. Two workshop pharmacies sent emails providing feedback about successful patient interactions using the checklist and another workshop pharmacy requested delivery of more checklists to use. None of these pharmacies were noted as using the checklist during simulated patient visits.

\section{DISCUSSION}

The aim of this research was to devise and evaluate a team-based intervention to formalise the role of 
Figure 3 Outcomes between cohorts and time points.
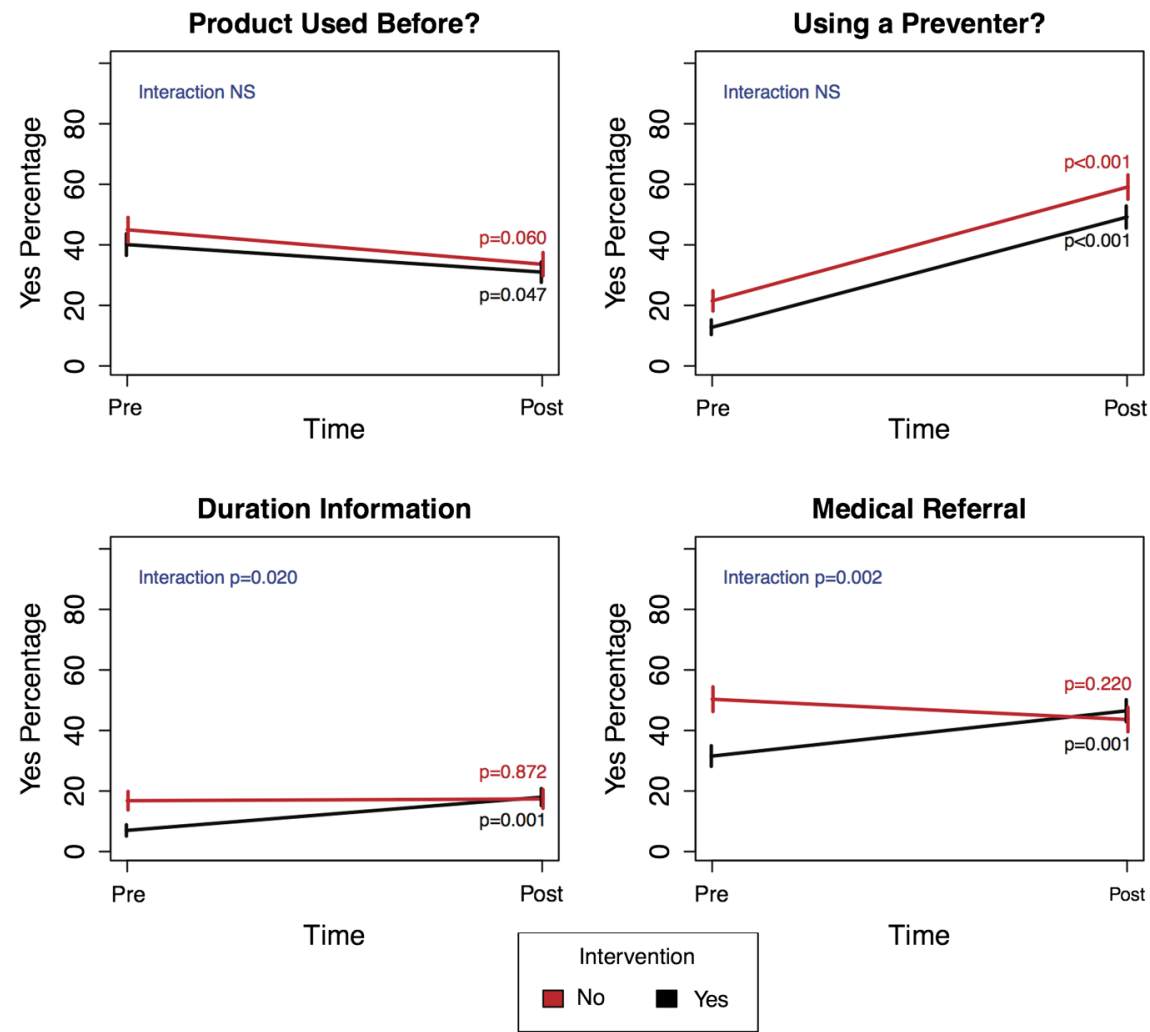

pharmacy assistants in order to improve SABA guidelinebased care in community pharmacy.

A key primary outcome of interest was increased patient medical referral due to identification of poor asthma control. The significant increase in medical referral observed in the intervention group indicates the potential effectiveness of this intervention. Another positive outcome observed was the increased incidence of discussions with patients about reliever duration and frequency of use. However, outcomes were variable and these positive results were not supported by results for other primary and secondary outcomes such as internal referral of patients from pharmacy assistants to pharmacists (indicating greater legislative compliance), increased device counselling or use of the "Asthma Medication Request Checklist' tool.

Some of the variability in the results may have been due to the workshop content and emphasis on particular elements of the guidelines. Inhaler device counselling was not an element of the guidelines specifically addressed in the workshop and only one question in the checklist related to previous device demonstration. In contrast, there was a greater focus on appropriate assessment of asthma control and medical referral criteria. This emphasis was borne out in the results and demonstrates that the content of a workshop can have an influence on outcomes. Furthermore, in this research, one person undertook all workshops, but the flexible, tailored approach could potentially lead to variable outcomes from multiple presenters who provide different emphases in a wider implementation programme. It is possible that constructing the workshop differently to focus on areas of poor practice related to the guidelines could have achieved better results.

Another reason for the variations in the success of this intervention may lie in the adaptations applied to the intervention during the course of the research. ${ }^{41} \mathrm{~A}$ thorough 'common-sense' approach was used in the design of the intervention. There was recognition, in choosing small group workshops, that community pharmacies are complex healthcare organisations requiring a team approach to implementation of new practice. However, in a naturalistic research setting, there are complexities that cannot always be predicted and controlled. Community pharmacies operate in a retail environment with long hours and are subject to seasonal fluctuations in workload. The workshops were initially offered in October and the poor uptake was attributed to the "busy Christmas retailing period'. Another issue was the difficulty in holding staff gatherings with extended trading hours and the large number of part-time and casual employees in the retail sector. Holding training outside of working hours also required investment on the part of business owner in terms of wages for staff. All these logistical issues inhibited uptake of the workshop intervention. This necessitated an adaptation of the workshop intervention ${ }^{41}$ that could be delivered via academic detailing.

Academic detailing was achievable on a much larger scale, but it did not facilitate team support for the initiative and relied on internal communications within the pharmacy to disseminate information and promote 
practice change. It also did not provide the opportunity to tailor the information to individual pharmacies. It is possible that the intervention could have achieved stronger positive outcomes if more workshops had been completed. Unfortunately, this study was not powered to detect a statistically significant difference between the academic detailing and workshop strategies. However, some trends were noticed that suggest the superiority of workshops compared to academic detailing. Both intervention groups were more likely to ask patients about preventer use at the postintervention time point, but there was a greater increase in the odds of this occurring in workshop pharmacies. Also workshop pharmacies asked significantly more assessment questions than academic detailing pharmacies. It is important that future research and intervention design should consider logistical issues to ensure successful implementation of guidelines. There are several taxonomies and frameworks available that may assist and provide a more systematic approach to intervention design and consideration of logistical issues. ${ }^{42-44}$

Despite the logistical problems encountered, the rationale in choosing small group workshops for interventions in community pharmacy seems to have merit, due to acknowledgement of the team-based environment that community pharmacists practice in. It is recognised that team-based change is likely to be slower and more incremental than changing the practice of an individual healthcare practitioner ${ }^{45}$ and hence the difficulty in achieving practice change in the community pharmacy setting, regardless of logistical issues. Results indicated some improvements in individual counselling and medical referral but not in system-level process improvements. Improvement in the outcomes of internal referral, device counselling and use of the new checklist necessitates workflow changes and this was not evident. Examples of partial or individual implementation success can be seen in the three pharmacies that either provided qualitative feedback about using the checklists or requested more checklists. Despite these self-reported indications of implementation success, none of the pharmacies were noted as using the checklist tool when visited by a simulated patient.

Historically, translating evidence into practice has been an incredibly slow and unpredictable process and it can take decades for empirical research to be implemented in routine medical practice. ${ }^{46-48}$ With practice change being a slower process for teams rather than individuals, it may have been that the dose and duration of this intervention were not substantial enough to achieve strongly significant outcomes and allow time for process adjustments. Reinforcement of the intervention was by way of resources, including access to a web page. Multiple workshops or detailing visits over a longer time frame may have provided stronger reinforcement of messages; opportunities to refine modified workflows and possibly could have improved outcomes. It is recognised that when new behaviours are attempted in the workplace, but routines are yet to be fully established, reinforcement can play a crucial role in maintenance and entrenchment of new practice. ${ }^{49}$ Given the team environment of community pharmacy, a substantial reinforcement programme should be factored into future interventions or guideline implementation initiatives.

Not only was team-based change required for intervention success but the intervention also needed to influence mutual engagement between pharmacy staff and patients. Patient engagement issues were addressed in a number of ways. Strategies such as communication skills training $^{27} 28$ and providing insight into the patient perspective $^{50}$ were based on evidence from the scientific literature. Other measures included recognition of the problems faced by pharmacy staff and the introduction of the Asthma Medication Request Checklist tool to assist with information gathering. However, it is possible that without an intervention directed specifically at patients, these measures were not sufficient to achieve the required change in patient beliefs and behaviours to achieve mutual engagement and information exchange. The work of Watson $e t a l^{27}$ found that the willingness of patients to provide information to pharmacy assistants was correlated with behavioural intentions and subjective norms. Without addressing the complexities underlying patient behaviour, substantive changes in asthma management may be unachievable. This suggests that there may be benefits in using a behavioural theory-based approach in intervention design, which is increasingly being recommended in the scientific literature. ${ }^{47} 5152$ However, a similar study, using the Theory of Planned Behaviour in intervention design and targeting pharmacy assistants, ultimately did not improve guideline compliance. ${ }^{28}$ At present, there is limited evidence of the benefits of the use of theory in the implementation of guidelines, particularly in the community pharmacy setting. $^{12}$

Direct pharmacist involvement and internal referral of patients from pharmacy assistants to pharmacists were considered important measures of legislative compliance. Legislation in Australia requires pharmacists to be directly involved in SABA sales. The results demonstrated no impact on either direct pharmacist involvement or internal referral due to the intervention. However, the large number of simulated patient visits for which the counsellor position could not be identified confounds interpretation of the true incidence of pharmacist involvement in consultations or of internal referral. The practical issue this identifies is that patients do not know whom they are talking to in almost half their visits to a community pharmacy. This situation is not conducive to optimal communication where patients can confidently seek and receive advice from a highly trained health professional: the community pharmacist. While no changes in internal referral were observed, both groups had an increase in the percentage of pharmacy assistants 'consulting' with a pharmacist, and this 
increase was significant in the control cohort. Consultation with a pharmacist means that the pharmacy assistant handles the entire patient interaction but refers to the pharmacist for advice or permission to conduct the sale. Such 'consultation' does not meet the requirements for legislative compliance and has been shown to worsen outcomes in previous research. ${ }^{8}$ Best outcomes are observed when successful internal referral occurs. ${ }^{8}$

The final significant observation from this research relates to the poor practice surrounding device counselling and demonstration of asthma inhalers. Despite being an inherent component of the SABA guidelines, device counselling was not routinely carried out at any stage or in any cohort of this research. Correct inhaler technique is crucial in optimising asthma treatment and minimising side effects. International guidelines recommend that pharmacists should contribute to patient education about inhalers and this is not occurring. ${ }^{53}$ The importance of this area, and the deficits in current practice, warrants specific attention. The results in this study are not unique and deficiencies in patient education on inhaler technique have been observed in other studies. ${ }^{85} 55$ Therefore, barriers to the provision of this service need further investigation.

\section{CONCLUSION}

Increases in medical referral indicate that asthma guideline compliance potentially can be improved in community pharmacy if implementation employs a team-based approach and involves pharmacy assistants, giving them a more defined and formalised role. However, the implementation intervention did not improve practice related to device counselling or internal referral/pharmacist involvement. These variable results may have been improved if more workshops had been undertaken. Logistical barriers to using workshops as an intervention strategy in this setting need to be overcome to test this hypothesis. Future research on guideline implementation to community pharmacy should consider the role of the pharmacy assistant and how to overcome logistical barriers to pharmacy participation in implementation activities. Consideration also needs to be given to the duration of an intervention and incorporation of reinforcement messages.

Acknowledgements The authors are grateful to the research assistants who completed the simulated patient shopping, the pharmacists who assisted with academic detailing and the community pharmacies that were willing to participate in the asthma workshops. A special thank you to Akos Bruz for the journey the authors took in developing the workshop videos. The authors thank Leon and Anne Levitt for sharing their amazing story and Anna Forrest and Jila Misaghian for their acting talent.

Contributors KW conceptualised and designed this research as part of her $\mathrm{PhD}$ studies, guided and supervised by CRS, KM, PAK and RC. KW and RC secured funding for the research from the Health Department of Western Australia. KW organised and ran the pharmacy asthma workshops, produced all workshops materials, participated in academic detailing and was an actor in the role-play video. KW developed resources and conducted training sessions for simulated patients and academic detailers. MT and KM completed the statistical analysis with input from KW. KW prepared an initial draft paper with all authors contributing to subsequent drafts and approving the final manuscript.

Funding KW is the recipient of an unrestricted $\mathrm{PhD}$ scholarship from AstraZeneca and a grant from the Health Department of Western Australia (grant agreement G05707). There are no further funding arrangements for this research.

Competing interests KW is the proprietor of a community pharmacy in Perth, Western Australia, and thus has a financial interest in community pharmacy.

Ethics approval Ethics approval was obtained from the University of Western Australia's Human Research and Ethics Committee (HREC RA/4/1/1588) to conduct mystery shopping and for the intervention (HREC RA/4/1/5000).

Provenance and peer review Not commissioned; externally peer reviewed.

Open Access This is an Open Access article distributed in accordance with the Creative Commons Attribution Non Commercial (CC BY-NC 4.0) license, which permits others to distribute, remix, adapt, build upon this work noncommercially, and license their derivative works on different terms, provided the original work is properly cited and the use is non-commercial. See: http:// creativecommons.org/licenses/by-nc/4.0/

\section{REFERENCES}

1. Global Initiative for Asthma (GINA). Global strategy for asthma management and prevention. Updated 2015. http://www. ginasthma. org

2. Boonsawat $\mathrm{W}$, Thompson PJ, Zaeoui U, et al. Survey of asthma management in Thailand - the asthma insight and management study. Asian Pac J Allergy Immunol 2015:33:14-20.

3. Maspero JF, Jardim JR, Aranda A, et al. Insights, attitudes, and perceptions about asthma and its treatment: findings from a multinational survey of patients from Latin America. World Allergy Organ J 2013;6:19.

4. Murphy KR, Meltzer EO, Blaiss MS, et al. Asthma management and control in the United States: results of the 2009 asthma insight and management survey. Allergy Asthma Proc 2012;33:54-64.

5. Reddel HK, Sawyer SM, Everett PW, et al. Asthma control in Australia: a cross-sectional web-based survey in a nationally representative population. Med J Aust 2015;202:492-7.

6. Rabe KF, Vermeire PA, Soriano JB, et al. Clinical management of asthma in 1999: the Asthma Insights and Reality in Europe (AIRE) study. Eur Respir J 2000;16:802-7.

7. Australian Government Department of Health and Ageing. Standard for the Uniform Scheduling of Medicines and Poisons (SUSMP). Feb 2016. http://www.tga.gov.au/industry/scheduling-poisons-standard. $\mathrm{htm}$

8. Schneider CR, Everett AW, Geelhoed E, et al. Measuring the assessment and counselling provided with the supply of non-prescription asthma reliever medication: a simulated patient study. Ann Pharmacother 2009;43:1512-18.

9. Pharmaceutical Society of Australia (PSA). Guidance for the provision of a Pharmacist Only medicine; short-acting beta-agonists (salbutamol and terbutaline). 2012. http://www.psa.org.au/download/ guidelines/Short-acting-beta-antagonist-protocol.pdf

10. Grol R, Buchan H. Clinical guidelines: what can we do to increase their use? Med J Aust 2006;185:301-2.

11. Grol R, Grimshaw J. From best evidence to best practice: effective implementation of change in patients' care. Lancet 2003;362:1225-30.

12. Watkins $\mathrm{K}$, Wood $\mathrm{H}$, Schneider $\mathrm{CR}$, et al. Effectiveness of implementation strategies for clinical guidelines to community pharmacy: a systematic review. Implement Sci 2015;10:151.

13. Armour C, Bosnic-Anticevich S, Brillant M, et al. Pharmacy Asthma Care Program (PACP) improves outcomes for patients in the community. Thorax 2007;62:496-502.

14. Barbanel D, Eldridge S, Griffiths C. Can a self-management programme delivered by a community pharmacist improve asthma control? A randomised trial. Thorax 2003;58:851-4.

15. Pharmacy Guild of Australia. Training Requirements for Pharmacy Medicines and Pharmacist Only Medicines (QCPP Version 2.3). 2014. http://www.qcpp.com/docs/librariesprovider4/ public-documents/resources/training/refreshertraining-v2-3 web.pdf? sfvrsn=0

16. Pharmacy Guild of Australia. Pre-enrolment Information GuideSupport the Supply of Pharmacy medicines and Pharmacist Only Medicines (SIRCHCS 201). 2014. http://www.guild.org.au/docs/ 
default-source/academy/Pharmacy-Assistants/pre-enrolment-forms2s3-v3-wa.pdf?sfvrsn=2

17. Pharmacy Guild of Australia. What is QCPP. 2015. http://www.qcpp. com/about-qcpp/what-is-qcpp

18. Watkins $\mathrm{K}$, Fisher $\mathrm{C}$, Misaghian $\mathrm{J}$, et al. A qualitative evaluation of the implementation of guidelines and a support tool for asthma management in primary care. Asthma Res Pract 2016;2:8.

19. Government of Western Australia. Poisons Regulations 1965 Amendment. Amendment, 2007. http://www.slp.wa.gov.au/gazette/ gg.nsf/act2? OpenView\&Start $=1 \&$ Count $=300 \&$ Expand $=100 \&$ RestrictToCategory=Poisons Act 1964-100

20. Government of Western Australia; Department of Health. Poisons Regulations 1965. 28 Nov 2012. http://www.slp.wa.gov.au/ legislation/statutes.nsf/main_mrtitle_1920_homepage.html

21. Clifford $\mathrm{R}$, Watkins $\mathrm{K}$, Schneider $\mathrm{C}$, et al. Implementation of short-acting beta agonist guidelines in Western Australia: a unique collaboration. Aust J Pharm 2012;93:97-102.

22. Schneider CR, Everett AW, Geelhoed E, et al. Provision of primary care to patients with chronic cough in the community pharmacy setting. Ann Pharmacother 2011;45:402-8.

23. Henderson J, Hancock KL, Armour C, et al. Asthma control in general practice-GP and patient perspectives compared. Aust Fam Physician 2013:42:740-3.

24. Marks GB, Abramson MJ, Jenkins CR, et al. Asthma management and outcomes in Australia: a nation-wide telephone interview survey. Respirology 2007:12:212-19.

25. National Asthma Council Australia (NAC), Asthma Australia, The Woolcock Institute of Medical Research, Pharmacy Guild of Australia. Short on Air Report 2010. https://www.nationalasthma.org au/living-with-asthma/resources/health-professionals/reports-andstatistics/short-on-air (accessed online Aug 2016).

26. Watkins K, Bourdin A, Trevenen M, et al. Opportunities for targeted interventions to improve the care of patients with asthma presenting to community pharmacy. University of Western Australia, 2016.

27. Watson MC, Johnston M, Entwistle V, et al. Using the theory of planned behaviour to develop targets for interventions to enhance patient communication during pharmacy consultations for non-prescription medicines. Int J Pharm Pract 2014;22: 386-96.

28. Watson MC, Cleland J, Inch J, et al. Theory-based communication skills training for medicine counter assistants to improve consultations for non-prescription medicines. Med Educ 2007;41:450-9.

29. Straus SE, Tetroe J, Graham ID, eds. Knowledge translation in healthcare: moving from evidence to practice. 2nd edn. Chichester, UK: Wiley-Blackwell, 2013.

30. Hakkennes S, Dodd K. Guideline implementation in allied health professions: a systematic review of the literature. Qual Saf Health Care 2008;17:296-300.

31. Squires JE, Sullivan K, Eccles MP, et al. Are multifaceted interventions more effective than single-component interventions in changing health-care professionals' behaviours? An overview of systematic reviews. Implement Sci 2014:9:152.

32. O'Brien MA, Rogers S, Jamtvedt G, et al. Educational outreach visits: effects on professional practice and health care outcomes. Cochrane Database Syst Rev 2007;CD000409.

33. Grimshaw JM, Thomas RE, MacLennan G, et al. Effectiveness and efficiency of guideline dissemination and implementation strategies. Health Technol Assess 2004;8:iii-iv, 1-72.

34. Pharmaceutical Society of Australia (PSA). Emergency contraception (EC) checklist. 2013. https://http://www.psa.org.au/ download/guidelines/3744 Emergency contraception checklist_V3. pdf

35. Schneider CR, Gudka S, Fleischer L, et al. The use of a written assessment checklist for the provision of emergency contraception via community pharmacies: a simulated patient study. Pharm Pract (Granada) 2013;11:127-31.

36. Australian Institute of Health and Welfare. Geographic distribution of asthma and chronic obstructive pulmonary disease hospitalisations in Australia 2007-08 to 2009-10. 2013. http://www. aihw.gov.au/WorkArea/DownloadAsset.aspx?id=60129542788

37. Pharmacy Registration Board of Western Australia. Main Premises Register. 2015. http://www.pharmacyboardwa.com.au/?n=Main Register

38. Schneider CR, Emery LJ, Clifford RM. The role of a protocol in the supply of anti-fungal treatment for vaginal thrush in the community pharmacy setting: a randomised controlled study [abstract]. Proceedings of the Australasian Pharmaceutical Science Association 2008 Conference; Canberra, 2008.

39. Salter SM, Delfante B, de Klerk S, et al. Pharmacists' response to anaphylaxis in the community (PRAC): a randomised, simulated patient study of pharmacist practice. BMJ Open 2014;4:e005648.

40. Salter SM, Loh R, Sanfilippo FM, et al. Demonstration of epinephrine autoinjectors (EpiPen and Anapen) by pharmacists in a randomised, simulated patient assessment: acceptable, but room for improvement. Allergy Asthma Clin Immunol 2014;10:49.

41. Elliott DS, Mihalic S. Issues in disseminating and replicating effective prevention programs. Prev Sci 2004:5:47-53.

42. Hoffmann TC, Glasziou PP, Boutron I, et al. Better reporting of interventions: template for intervention description and replication (TIDieR) checklist and guide. BMJ 2014;348:g1687.

43. Hofmann PA. Critical path method: an important tool for coordinating clinical care. Jt Comm J Qual Improv 1993;19:235-46.

44. Schulz R, Czaja SJ, McKay JR, et al. Intervention taxonomy (ITAX): describing essential features of interventions. Am J Health Behav 2010;34:811-21.

45. Overton GK, McCalister P, Kelly D, et al. Practice-based small group learning: how health professionals view their intention to change and the process of implementing change in practice. Med Teach 2009;31:e514-20.

46. Carlfjord $\mathrm{S}$, Lindberg $\mathrm{M}$, Bendtsen $\mathrm{P}$, et al. Key factors influencing adoption of an innovation in primary health care: a qualitative study based on implementation theory. BMC Fam Pract 2010;11:60.

47. ICEBeRG Research Group. Designing theoretically-informed implementation interventions. Implement Sci 2006;1:4.

48. Sussman S, Valente TW, Rohrbach LA, et al. Translation in the health professions: converting science into action. Eval Health Prof 2006;29:7-32.

49. Silversin J, Kornacki MJ. Implementing change: from ideas to reality. Fam Pract Manag 2003;10:57-62.

50. Horne R, Price D, Cleland J, et al. Can asthma control be improved by understanding the patient's perspective? BMC Pulm Med 2007;7:8.

51. Davies P, Walker AE, Grimshaw JM. A systematic review of the use of theory in the design of guideline dissemination and implementation strategies and interpretation of the results of rigorous evaluations. Implement Sci 2010;5:14

52. Eccles M, Grimshaw J, Walker A, et al. Changing the behavior of healthcare professionals: the use of theory in promoting the uptake of research findings. J Clin Epidemiol 2005;58:107-12.

53. National Heart, Lung, and Blood Institute. Guidelines for the Diagnosis and Management of Asthma: Expert Panel Report (EPR-3), 2007. http://www.nhlbi.nih.gov/files/docs/guidelines/ asthsumm.pdf

54. Barton C, Proudfoot J, Amoroso C, et al. Management of asthma in Australian general practice: care is still not in line with clinical practice guidelines. Prim Care Respir J 2009;18:100-5.

55. Melani AS, Bonavia M, Cilenti V, et al. Inhaler mishandling remains common in real life and is associated with reduced disease control. Respir Med 2011;105:930-8. 